\title{
Severe Hypercalcemia as the Initial Presentation of a Neuroendocrine Carcinoma of Unknown Primary Site: A Case Report
}

\author{
Hafeez Shaka ${ }^{1}$, Sairam Raghavan ${ }^{1}$ \\ 1. Internal Medicine, John H. Stroger Jr. Hospital of Cook County, Chicago, USA
}

Corresponding author: Hafeez Shaka, sagehafeez@gmail.com

\begin{abstract}
Hypercalcemia is a common paraneoplastic syndrome that is associated with many malignancies. Hypercalcemia develops in malignancies through various mechanisms. Parathyroid hormone-related protein (PTHrP) is secreted by malignancy involving the lungs, breast, colorectum, bladder, and, rarely, neuroendocrine tumors. This is a rare case of severe hypercalcemia as the initial presentation of a highgrade metastatic neuroendocrine tumor of an unknown primary site.
\end{abstract}

Categories: Endocrinology/Diabetes/Metabolism, Internal Medicine, Oncology

Keywords: humoral hypercalcemia of malignancy, neuroendocrine carcinoma, carcinoma of unknown primary, paraneoplastic syndrome, parathyroid hormone related peptide

\section{Introduction}

Paraneoplastic syndromes are becoming increasingly prevalent in medicine, as our understanding of these conditions grows. The endocrine system is most commonly affected by paraneoplastic syndromes [1]. Hypercalcemia is a common finding in patients with malignancies and is present in approximately $10 \%$ of patients with advanced cancer. It also represents a poor prognosis. There are several mechanisms by which this may happen, but the excess secretion of parathyroid hormone-related peptide (PTHrP) is thought to account for a majority of the cases [2]. We report a case of severe hypercalcemia caused by a high-grade neuroendocrine tumor of unknown primary.

\section{Case Presentation}

A 29-year-old African American lady was brought into the emergency department with abdominal pain and recurrent headaches for four weeks, dizziness for a week, and an episode of syncope. She had crampy abdominal pain that was mild and progressive, associated with constipation but no nausea, vomiting, or abdominal distension. Headaches were mainly frontal, lasting a few hours, and transiently relieved with Tylenol. She denied any visual changes, photosensitivity, or eye pain. She developed dizziness about a week prior, which was worsened on standing, and improved on lying down. She fell a few times. She had a syncopal event lasting a few minutes with altered mental status following awakening, hence she was brought

for further evaluation. The review of systems was significant for a 10-pound weight loss in a month, palpitations, fatigue polydipsia, and polyuria.

On presentation, her vital signs were within normal limits, except for mild tachypnea. Physical examination showed an obese lady, who was alert and fully oriented, with dry oral mucosa, pale conjunctiva, and an enlarged neck mass.

Laboratory investigations showed moderate microcystic anemia, creatinine of $1.7 \mathrm{mg} / \mathrm{dL}$ (normal range 0.6$1.2 \mathrm{mg} / \mathrm{dL}$ ), calcium of $21 \mathrm{mg} / \mathrm{dL}$ (normal range $8.5-10.5 \mathrm{mg} / \mathrm{dL}$ ), phosphate of $2.2 \mathrm{mg} / \mathrm{dL}$ (normal range 2.5 $4.5 \mathrm{mg} / \mathrm{dL}$ ), and lipase of $450 \mathrm{U} / \mathrm{L}$ (normal range 5-55 U/L). Other investigations included parathyroid hormone (PTH) of $4.36 \mathrm{pg} / \mathrm{mL}$ (normal range $12-88 \mathrm{pg} / \mathrm{L}$ ), 25 hydroxy vitamin $\mathrm{D}$ of $<7 \mathrm{ng} / \mathrm{mL}$ (normal range 30-100 ng/mL), 1, 25 dihydroxy vitamin D of $18 \mathrm{ng} / \mathrm{mL}$ (normal range $18-72 \mathrm{ng} / \mathrm{mL}$ ), PTHrP of $33 \mathrm{pg} / \mathrm{mL}$ (normal range $14-27 \mathrm{pg} / \mathrm{mL}$ ), and TSH of $0.20 \mathrm{uIU} / \mathrm{mL}$ (normal range $0.34-5.60 \mathrm{uIU} / \mathrm{mL}$ )

Magnetic resonance imaging (MRI) of the brain showed a $3.6 \mathrm{~cm}$ dural-based left frontal lobe mass invading the inner table of the left frontal calvarium and extending into the left frontal sinus (Figure 1). A computed tomography (CT) scan of the neck showed marked heterogeneous enlargement of the right thyroid gland measuring approximately $8.7 \times 5.2 \times 11 \mathrm{~cm}$ (Figure 2). CT of the abdomen and pelvis showed an enlarged uterus with heterogeneous attenuation and enlarged endometrial canal, approximately 9.8 x 13.4 x $17.3 \mathrm{~cm}$ (Figure 3). 


\section{Cureus}

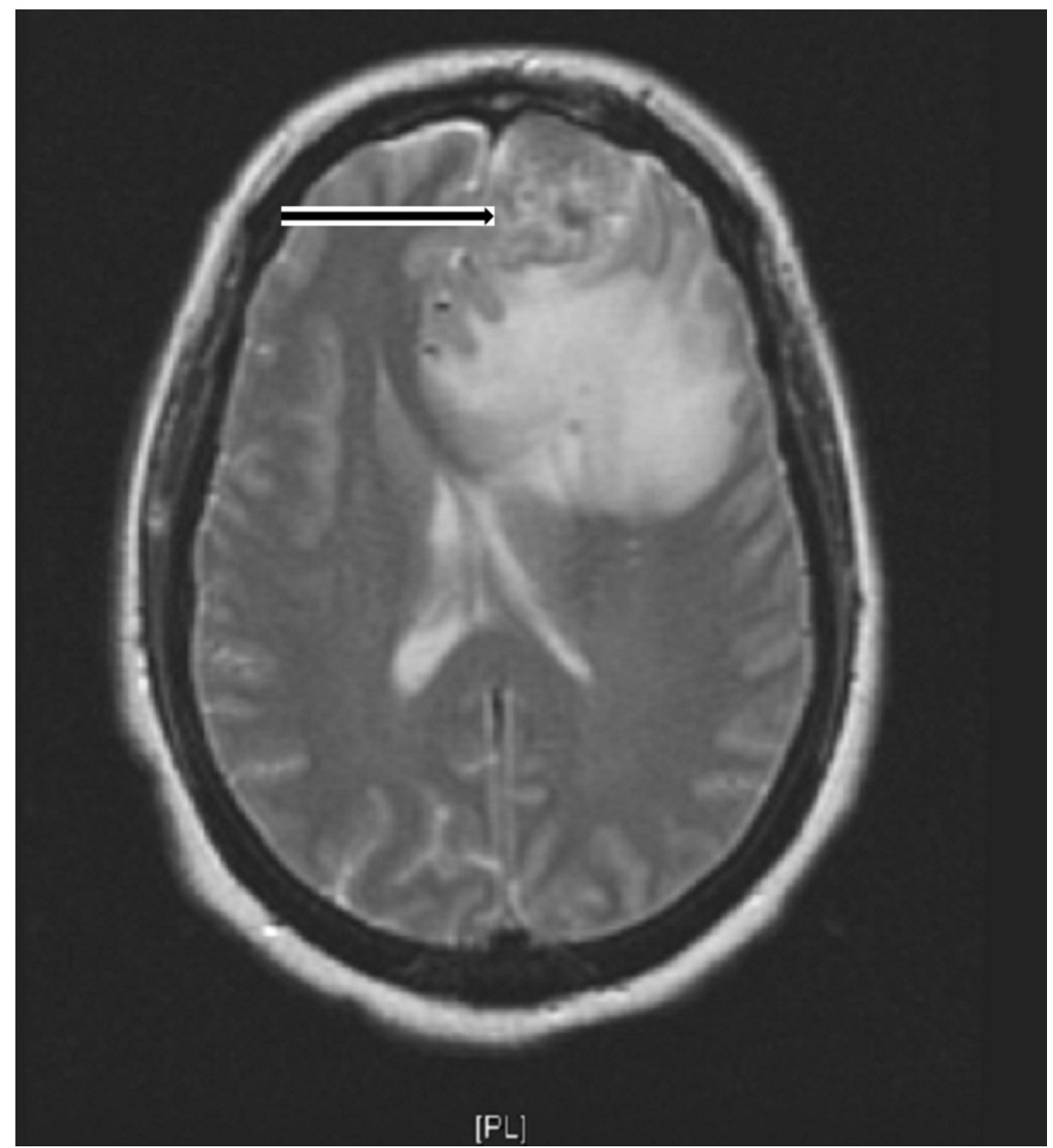

FIGURE 1: T2 Weighted MRI brain showing left frontal mass (black arrow) with surrounding vasogenic edema and midline shift

MRI: magnetic resonance imaging 


\section{Cureus}

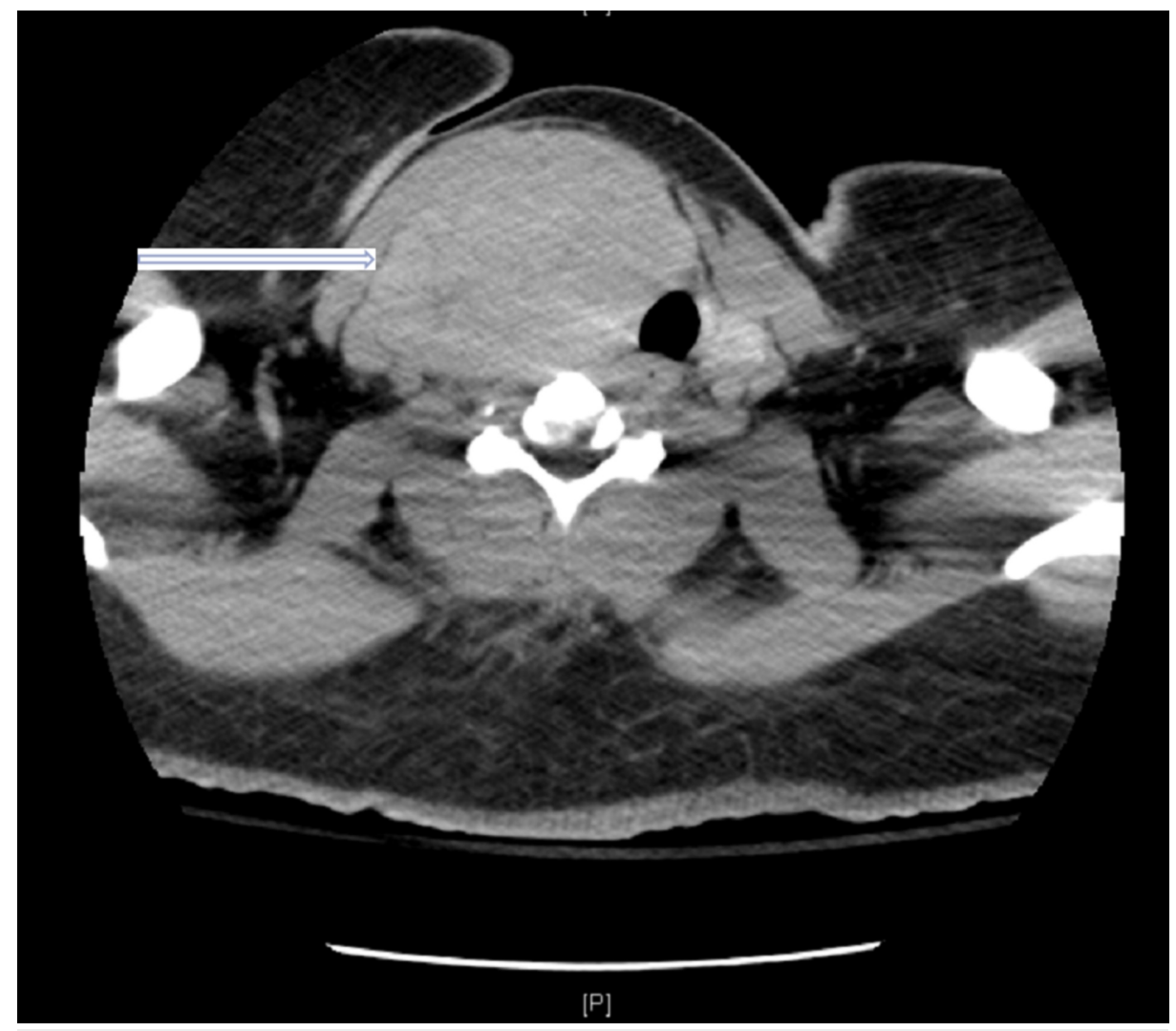

FIGURE 2: Axial view of CT neck with intravenous contrast showing right thyroid mass (white arrow) with tracheal deviation

CT: computed tomography 


\section{Cureus}

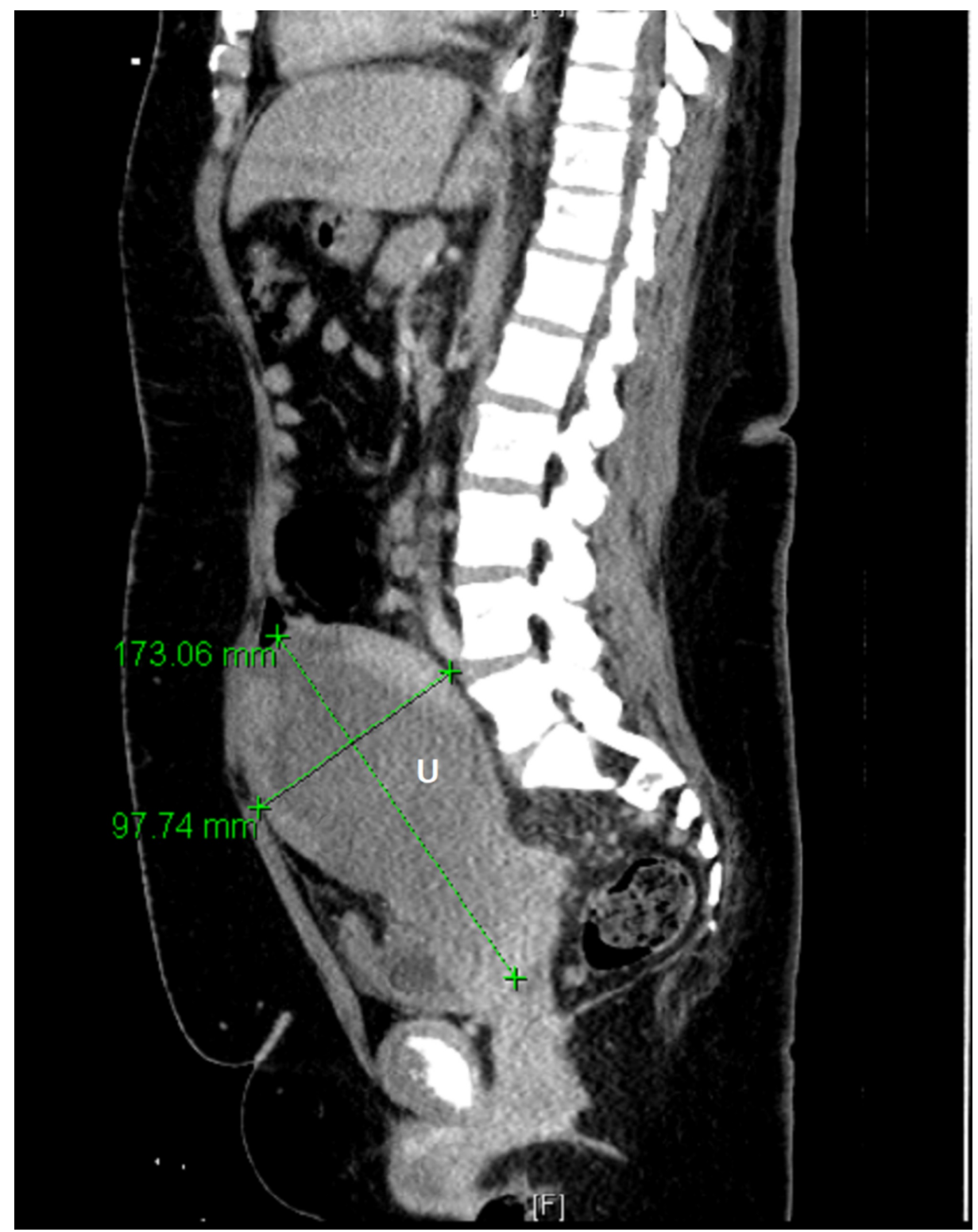

FIGURE 3: Sagittal view of CT abdomen and pelvis with intravenous contrast, showing large heterogeneous uterine mass (U)

CT: computed tomography

Further imaging revealed generalized lymphadenopathy, multiple hypodense liver lesions, infiltrations, and edema of the pancreatic head, and mixed lytic and sclerotic osseous lesions in the pelvis, with pathologic fracture of the right pubic ramus. An assessment of symptomatic severe hypercalcemia likely from metastatic neoplasm, acute interstitial pancreatitis, acute kidney injury, and brain lesion with mass effect was made and she was admitted into the intensive care unit for management. She received high-flow intravenous (IV) fluids, IV pamidronate, IV dexamethasone, and IV levetiracetam. Her calcium downtrended rapidly from 21 to 10.8 in three days of management, and she showed corresponding clinical improvement.

Multiple pathological results from biopsies of uterine, liver, thyroid, and brain masses showed high-grade neuroendocrine neoplasms of an unknown primary site.

\section{Discussion}

Paraneoplastic syndromes can be the initial presentation of multiple malignancies. Hypercalcemia in malignancy is caused by four known mechanisms. The production of PTHrP is the most common mechanism, accounting for $>80 \%$ of cases of hypercalcemia in malignancy and called humoral hypercalcemia of malignancy (HHM). Other mechanisms include osteolytic metastases causing excessive 
calcium release from the bone, the ectopic activity of 1-alpha hydroxylase enzyme, leading to excessive production of the active form of vitamin D, and ectopic production of PTH [3-5].

The majority of cases of HHM are associated with squamous cell carcinomas, renal, bladder, breast, ovarian, prostate, colorectal carcinomas, leukemia, and lymphomas [6]. Rarely, HHM has been identified in patients with neuroendocrine tumors of the pancreas [7-10], the esophagus [11], and the very rare ovarian non-small cell neuroendocrine carcinoma [12]. Our patient had HHM, diagnosed by severely elevated calcium, suppressed PTH, elevated PTHrP, and low vitamin D levels. Her clinical presentation was also likely due to hypercalcemia, with abdominal pain, polyuria, fatigue, and altered mental status in the setting of hypercalcemia being characteristic. These symptoms improved with the correction of hypercalcemia without definitive malignancy directed therapy.

The primary site of this biopsy-confirmed high-grade neuroendocrine tumor was difficult to establish. She had gross lesions in the brain, thyroid, liver, and uterus. Poorly differentiated high-grade neuroendocrine tumors can originate in the gastrointestinal tract, bladder, cervix, and prostate and due to rapid progression, management is warranted even when the primary site has not been established [13-14].

Although symptomatic HHM was the initial presentation leading to the diagnosis of the above metastatic neuroendocrine tumor, it is a marker of advanced disease and portends a poor prognosis [15-16].

\section{Conclusions}

Severe hypercalcemia can be the initial presentation of high-grade neuroendocrine carcinoma, which is often mediated by PTHrP. This presentation is, however, a very poor prognostic marker.

\section{Additional Information \\ Disclosures}

Human subjects: Consent was obtained by all participants in this study. Conflicts of interest: In compliance with the ICMJE uniform disclosure form, all authors declare the following: Payment/services info: All authors have declared that no financial support was received from any organization for the submitted work. Financial relationships: All authors have declared that they have no financial relationships at present or within the previous three years with any organizations that might have an interest in the submitted work. Other relationships: All authors have declared that there are no other relationships or activities that could appear to have influenced the submitted work.

\section{References}

1. Pelosof LC, Gerber DE: Paraneoplastic syndromes: an approach to diagnosis and treatment. Mayo Clin Proc. 2010, 85:838-854. 10.4065/mcp.2010.0099

2. Dimitriadis GK, Angelousi A, Weickert MO, Randeva HS, Kaltsas G, Grossman A: Paraneoplastic endocrine syndromes. Endocrine-related cancer. 2017, 24:173-190. 10.1530/ERC-17-0036

3. Mirrakhimov AE: Hypercalcemia of malignancy: an update on pathogenesis and management . N Am J Med Sci. 2015, 7:483-493. 10.4103/1947-2714.170600

4. Tebben PJ, Singh RJ, Kumar R: Vitamin D-mediated hypercalcemia: mechanisms, diagnosis, and treatment . Endocr Rev. 2016, 37:521-547. 10.1210/er.2016-1070

5. Doyle MA, Malcolm JC: An unusual case of malignancy-related hypercalcemia. Int J Gen Med. 2013, 7:21-27. 10.2147/IJGM.S51302

6. Pecherstorfer M, Schilling T, Blind E, Zimmer-Roth I, Baumgartner G, Ziegler R, Raue F: Parathyroid hormone-related protein and life expectancy in hypercalcemic cancer patients. J Clin Endocrinol Metab. 1994, 78:1268-1270. 10.1210/jcem.78.5.8175989

7. Clemens P, Gregor M, Lamberts R: Pancreatic neuroendocrine tumor with extensive vascularisation and parathyroid hormone-related protein (PTHrP) - associated hypercalcemia of malignancy. Exp Clin Endocrinol Diabetes. 2001, 109:378-385. 10.1055/s-2001-17411

8. Mussig K, Petersenn S, Wehrmann M, Horger M, Vierling P, Häring HU, Gallwitz B: Somatostatin receptor expression in a parathyroid hormone-related peptide-secreting pancreatic neuroendocrine tumour causing severe hypercalcaemia. Eur J Gastroenterol Hepatol. 2007, 19:719-723.

9. Stavri GT, Pritchard GA, Williams EJ, Stamatakis JD: Somatostatinoma of the pancreas with hypercalcaemia. A case report. Eur J Surg Oncol. 1992, 18:298-300.

10. Papazachariou IM, Virlos IT, Williamson RC: Parathyroid hormone-related peptide in pancreatic neuroendocrine tumours associated with hypercalcaemia. HPB (Oxford). 2001, 3:221-225. $10.1080 / 136518201753242253$

11. Atsumi Y, Iwasaki E, Hoshino M, et al.: Case report; small cell neuroendocrine carcinoma of the esophagus producing parathyroid hormone-related peptide with humoral hypercalcemia [Article in Japanese]. Nihon Naika Gakkai Zasshi. 2014, 103:741-743.

12. Ohira S, Itoh K, Shiozawa T, et al.: Ovarian non-small cell neuroendocrine carcinoma with paraneoplastic parathyroid hormone-related hypercalcemia. Int J Gynecol Pathol. 2004, 23:393-397. 10.1097/01.pgp.0000139655.18062.12

13. Strosberg JR, Coppola D, Klimstra DS, Phan A, Kulke M, Wiseman G, Kvols L: The NANETS consensus guidelines for the diagnosis and management of poorly differentiated (high-grade) extrapulmonary neuroendocrine carcinomas. Pancreas. 2010, 39:799-800. 10.1097/MPA.0b013e3181ebb56f 


\section{Cureus}

14. Koumarianou A, Chatzellis E, Boutzios G, Tsavaris N, Kaltsas G: Current concepts in the diagnosis and management of poorly differentiated gastrointestinal neuroendocrine carcinomas. Endokrynol Pol. 2013, 64:60-72. 10.4322/acr.2018.025

15. Ralston SH, Gallacher SJ, Patel U, Campbell J, Boyle IT: Cancer-associated hypercalcemia: Morbidity and mortality. Clinical experience in 126 treated patients. Ann Intern Med. 1990, 112:499-504. 10.7326/00034819-112-7-499

16. Hamilton F, Carroll R, Hamilton W, Salisbury C: The risk of cancer in primary care patients with hypercalcaemia: A cohort study using electronic records. Br J Cancer. 2014, 111:1410-2.

10.1038/bjc.2014.433 